Acta Crystallographica Section E

Structure Reports

Online

ISSN 1600-5368

\section{Lars Kr. Hansen, ${ }^{a} *$ German L. Perlovich $^{b, c}$ and Annette Bauer-Brandl $^{b}$}

${ }^{a}$ Department of Chemistry, University of Tromsø, 9037 Tromsø, Norway, 'bepartment of Pharmaceutics and Biopharmaceutics, University of Tromsø, 9037 Tromsø, Norway, and 'Institute of Solution Chemistry, Russian Academy of Sciences, 153045 Ivanovo, Russian Federation

Correspondence e-mail: larsk@chem.uit.no

\section{Key indicators}

Single-crystal X-ray study

$T=293 \mathrm{~K}$

Mean $\sigma(\mathrm{C}-\mathrm{C})=0.003 \AA$

$R$ factor $=0.046$

$w R$ factor $=0.033$

Data-to-parameter ratio $=9.3$

For details of how these key indicators were automatically derived from the article, see http://journals.iucr.org/e.

\title{
Redetermination of 3-hydroxybenzamide
}

The crystal structure of the title compound, $\mathrm{C}_{7} \mathrm{H}_{7} \mathrm{NO}_{2}$, has been redetermined [Katsube, Y. (1966). Bull. Chem. Soc. Jpn, 39, 2576-2588] to higher precision and with the hydrogenbonding scheme established.

\section{Comment}

Hydroxybenzamides (I), (II) and (III) are often used as prodrug compounds to model various physico-chemical processes of the drug molecules. Their different hydrogen-bonding patterns help to establish their structures and determine their solubilities.<smiles>NC(=O)c1ccccc1O</smiles>

(I)<smiles>NC(=O)c1cccc(O)c1</smiles>

(II)<smiles>NC(=O)c1ccc(O)cc1</smiles>

(III)
The crystal structure of 2-hydroxybenzamide (salicylamide), (I), has been described in detail in the literature (Sasada et al., 1964; Pertlik, 1990), whereas the structure of 4hydroxybenzamide, (III), has not been reported at all. The structure of 3-hydroxybenzamide, (II), was studied some time ago by Katsube (1966) to moderate precision. Here we present a high-precision redetermination of (II) (Fig. 1) and describe its hydrogen-bonding scheme (Table 1).

The bond lengths and angles for (II) are within their normal ranges (Allen et al., 1987). The data obtained by us for the non-H atoms are consistent with Katsube's, but improved by about a factor of twenty in precision. For example, $\mathrm{C} 7-\mathrm{O} 1=$ 1.245 (2) §, compared with 1.24 (7) $\AA$ in Katsube's study. The dihedral angle between the mean plane of the aromatic ring and the plane of $\mathrm{C} 7 / \mathrm{N} 1 / \mathrm{O} 1$ is $22.9(2)^{\circ}$.

The packing of (II) is shown in Fig. 2. The molecules form (101) layers held together by $\mathrm{N}-\mathrm{H} \cdots \mathrm{O}$ and $\mathrm{O}-\mathrm{H} \cdots \mathrm{O}$ hydrogen bonds. The layers interact with each other by van der Waals forces. The hydrogen-bond network can be described by the graph set assignments introduced by Etter (1990) as $C(4), C(8)$, and $R_{2}^{2}(14)$.
Received 27 March 2007 Accepted 29 March 2007

\section{Experimental}

A commercial sample of 3-hydroxybenzamide (Sigma-Aldrich Co. Ltd, St Louis, USA) was used. Crystals of (II) were grown by slow evaporation of a methanol solution. 


\section{Crystal data \\ $\mathrm{C}_{7} \mathrm{H}_{7} \mathrm{NO}_{2}$ \\ $M_{r}=137.14$ \\ Monoclinic, $P 2_{b} / n$ \\ $a=10.873(5) \AA$ \\ $b=5.064(2) \AA$ \\ $c=11.641(5) \AA$ \\ $\beta=92.414(11)^{\circ}$ \\ Data collection}

Rigaku Saturn diffractometer

Absorption correction: multi-scan

(Jacobson, 1998)

$T_{\text {min }}=0.938, T_{\text {max }}=0.989$

\section{Refinement}

$R\left[F^{2}>2 \sigma\left(F^{2}\right)\right]=0.046$

$w R\left(F^{2}\right)=0.033$

$S=1.80$

1103 reflections

119 parameters

Table 1

Hydrogen-bond geometry $\left(\AA{ }^{\circ}\right)$.

\begin{tabular}{lllll}
\hline$D-\mathrm{H} \cdots A$ & $D-\mathrm{H}$ & $\mathrm{H} \cdots A$ & $D \cdots A$ & $D-\mathrm{H} \cdots A$ \\
\hline $\mathrm{N} 1-\mathrm{H} 8 \cdots \mathrm{O} 2^{\mathrm{i}}$ & $0.93(2)$ & $2.07(2)$ & $2.990(2)$ & $168(2)$ \\
$\mathrm{N} 1-\mathrm{H} 7 \cdots \mathrm{O} 1^{\text {ii }}$ & $0.90(2)$ & $2.15(2)$ & $2.988(2)$ & $153(2)$ \\
$\mathrm{O} 2-\mathrm{H} 6 \cdots 1^{\text {iii }}$ & $0.97(2)$ & $1.86(2)$ & $2.798(2)$ & $164(2)$ \\
\hline
\end{tabular}

Symmetry codes: (i) $x+\frac{1}{2},-y+\frac{3}{2}, z-\frac{1}{2}$; (ii) $x, y+1, z$; (iii) $-x+2,-y+1,-z+1$.

The crystals were of poor quality and weakly diffracting, which accounts for the low fraction of measured reflections. The $\mathrm{H}$ atoms were located in difference maps and their positions and $U_{\text {iso }}$ values were freely refined $[\mathrm{C}-\mathrm{H}=0.963$ (18)-1.007 (18) $\AA$ ].

Data collection: CrystalClear (Rigaku/MSC, 2005); cell refinement: CrystalClear; data reduction: CrystalStructure (Rigaku/MSC, 2005); program(s) used to solve structure: SIR92 (Altomare et al., 1994); program(s) used to refine structure: CRYSTALS (Betteridge et al., 2003); molecular graphics: ORTEX (McArdle, 1993) and ORTEPIII (Burnett \& Johnson, (1996); software used to prepare material for publication: CrystalStructure.

\section{References}

Allen, F. H., Kennard, O., Watson, D. G., Brammer, L., Orpen, A. G. \& Taylor, R. (1987). J. Chem. Soc. Perkin Trans. 2, pp. S1-19.

Altomare, A., Cascarano, G., Giacovazzo, C., Guagliardi, A., Burla, M. C., Polidori, G. \& Camalli, M. (1994). J. Appl. Cryst. 27, 435.

Betteridge, P. W., Carruthers, J. R., Cooper, R. I., Prout, K. \& Watkin, D. J. (2003). J. Appl. Cryst. 36, 1487.

Burnett, M. N. \& Johnson, C. K. (1996). ORTEPIII. Report ORNL-6895. Oak Ridge National Laboratory, Tennessee, USA.

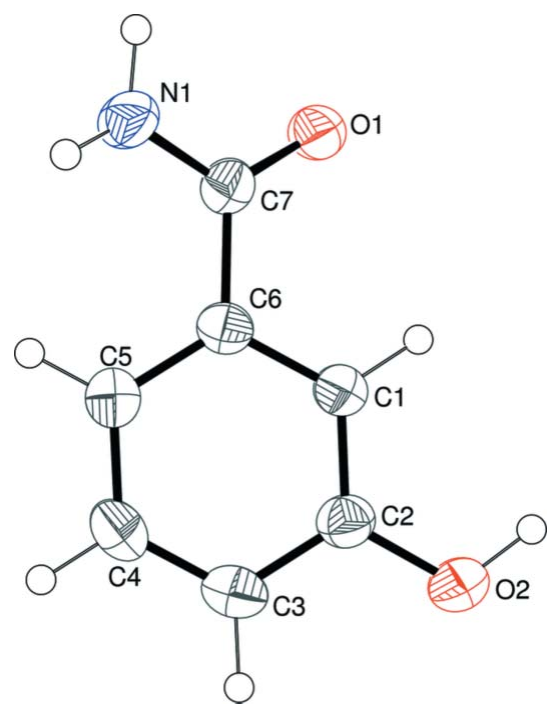

Figure 1

The molecular structure of (I), showing displacement ellipsoids drawn at the $40 \%$ probability level (arbitrary spheres for the $\mathrm{H}$ atoms).

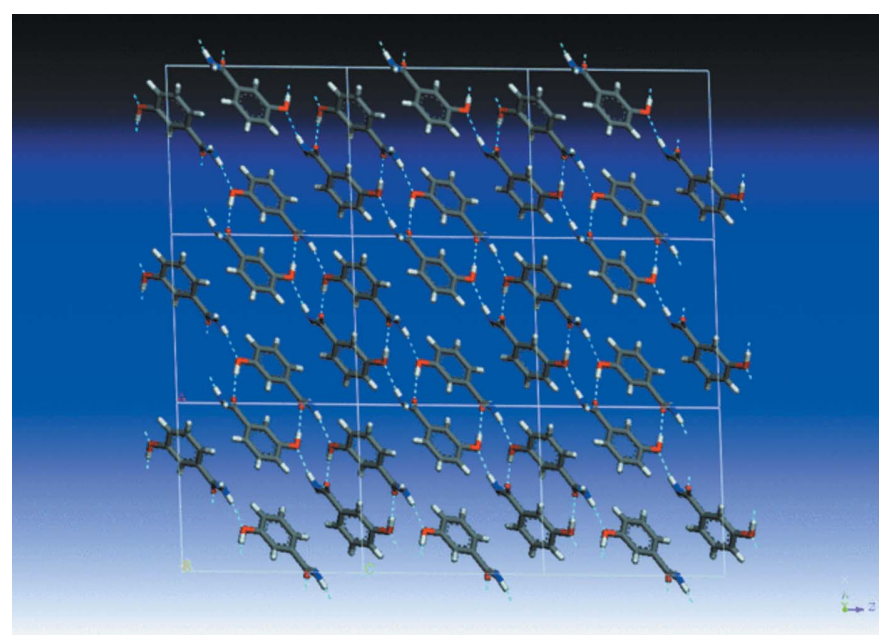

Figure 2

The packing of (I) with hydrogen bonds indicated by dashed lines.

Etter, M. C. (1990). Acc. Chem. Res. 23, 120-126.

Jacobson, R. (1998). Private communication to the Rigaku Corporation, Tokyo, Japan.

Katsube, Y. (1966). Bull. Chem. Soc. Jpn, 39, 2576-2588.

McArdle, P. (1993). J. Appl. Cryst. 26, 752.

Pertlik, F. (1990). Monatsh. Chem. 121, 129-139.

Rigaku/MSC (2005). CrystalClear (Version SM-1.4.0 b2 and CrystalStructure (Version 3.7.0). Rigaku/MSC, The Woodlands, Texas, USA.

Sasada, Y., Takano, T. \& Kakudo, M. (1964). Bull. Chem. Soc. Jpn, 37, 940-946. 